\title{
Optimal Operation and Financing Decisions in Green Supply Chain with a Capital-Constrained Manufacturer
}

\author{
Lijuan Xia $\mathbb{D},{ }^{1}$ Lixin Qiao $\mathbb{D},{ }^{1}$ Xiaochen Ma $\mathbb{D},{ }^{2}$ Yuanze Sun $\mathbb{D},{ }^{3}$ and Yongli Li $\mathbb{D}^{1}$ \\ ${ }^{1}$ School of Economics and Management, Harbin Institute of Technology, Harbin 150001, China \\ ${ }^{2}$ Business School, China University of Political Science and Law, Beijing 100088, China \\ ${ }^{3}$ School of Mathematics, Hefei University of Technology, Hefei 230009, China \\ Correspondence should be addressed to Lixin Qiao; qiaolixin_hit@126.com
}

Received 29 May 2021; Accepted 9 July 2021; Published 19 July 2021

Academic Editor: Wei Zhang

Copyright (C) 2021 Lijuan Xia et al. This is an open access article distributed under the Creative Commons Attribution License, which permits unrestricted use, distribution, and reproduction in any medium, provided the original work is properly cited.

Capital constraint, immensely existing in practice, became major stressors for manufacturers during the green research and development (R \& D) triggered by managers integrating green concept into their business models. Considering the initial capital of a capital-constrained manufacturer, this paper formulates a Stackelberg game model comprising a manufacturer and a retailer, to discuss the optimal operation and financing decisions under the bank financing channel and trade credit financing channel, to detect the relationship between the manufacturer's initial capital and green R \& D investment, and to find which financing channel is better by comparing the two financing channels when the same initial capital is set. According to the above analysis, the results find that the capital-constrained manufacturer prefers financing only when meeting certain conditions. Furthermore, financing might be detrimental to the manufacturer but always beneficial to the retailer. Especially, under trade credit financing channel, the profit improvement of the retailer is higher than the manufacturer in the same financing channel, which suggests that the retailer has strong internal motivation to cooperate with the manufacturer from the perspective of financing.

\section{Introduction}

Nowadays, it is already accepted that the green R \& D has become an important way for enterprises to meet market access standards and attain market competitive advantages [1-3]. Over the years, some manufacturers have adopted the green concept in their supply chain management and effectively improved their economic and environmental performances [4]. However, some manufacturers limited by capital constraints, especially small and medium-sized enterprises (SMEs), are still struggling to implement green R \& $\mathrm{D}$ [5]. Financing is an efficient way to solve the capitalconstrained problem; for the capital-constrained manufacturer, bank financing and credit financing are the two main financing channels. More specifically, bank financing refers to the manufacturer obtaining loans from banks [6], while trade credit financing refers to a supply chain's internal financing in which enterprises provide financial support for capital-constrained supply chain members in the form of early or delayed payment $[7,8]$. Considering manufacturer initial capital, how does the initial capital effect the green R \& D investment and profits of the manufacturer? Comparing bank financing with trade credit financing, which is better for the capital-constrained manufacturer? All the abovementioned issues inspired us to detect the optimal operation and financing decisions of the capital-constrained manufacturer under two available financing channels that are widely applied in practice, and then to explore the financing preference of manufacturers in different situations.

Once these questions are answered, we can provide managers with financing decision-making reference. Financing decision is one of the important management aspects of managers; if solved, it can guide managers to choose the appropriate financing channel and improve their profits. Although many literatures on financing provided relevant evidences, and revealed the benefits of financing to capitalconstrained enterprises [9-11], only a few scholars have concentrated on the capital-constrained manufacturer in the 
green supply chain. For example, Cao et al. [12] studied the ordering problem of capital-constrained manufacturers under supplier financing and bank financing. Nowadays, the green $\mathrm{R} \& \mathrm{D}$ financing problem has not been solved. To further enrich the existing research, we adopt the Stackelberg game model, which can correctly describe the decisionmaking process of supply chain members, to analyze the operation and financing decisions of manufacturers facing green R \& D capital-constrained, and endeavor to remedy the limitation of existing researches in the green supply chain.

To answer the abovementioned research questions, this paper takes the green supply chain composed of a single capital-constrained manufacturer and a single capital ample retailer as the research objects. To generalize our result insights, our paper mainly focuses on two common financing channels, bank and trade credit, in the green supply chain. By constructing the Stackelberg game model under no financing, bank financing, and trade credit financing, we explore the optimal products' green degree, wholesale price, and retail price under the three situations. In addition, this paper further considers the initial capital, analyzes manufacturer financing preference, and assesses the impact of different financing strategies on profits of the manufacturer and retailer.

Given the growth of the green supply chain and capital constraints in practice, it is a significant reference for supply chain management to understand how the initial capital affects the green supply chain decisions. According to this, we investigate the operation and financing problems when a manufacturer's initial capital is insufficient to invest in the demanded green R \& D. Our main contributions are as follows. (1) Considering that many previous researches on green supply chain management assumed that manufacturers have sufficient capital, we extend research to the scenario of capital constraint where the capital-constrained manufacturer is faced with the challenge of integrating green concept into its business. (2) This paper particularly concentrates on the initial capital because more related researches on supply chain financing pay less attention to the initial capital. Hence, we creatively incorporate the initial capital into the Stackelberg model and study the problem of capital-constrained green R \& D. (3) By comparing the financing strategies of the manufacturer, we explore the manufacturer's relative financing preference when the initial capital is constrained. Although some studies have explored the choice of supply chain financing channel, the majority of them focused on the capital-constrained retailer or inventory decision; financing related to manufacturers need to be further detected.

The remainder of the paper is organized as follows. Section 2 reviews the related work. Section 3 provides problem description and basic assumptions. Section 4 establishes a Stackelberg game model and analyzes the optimal operation and financing decisions. Section 5 conducts the numerical analysis. Finally, the conclusion is provided in Section 6.

\section{Related Work}

This paper belongs to the interface between green supply chain and financing. According to the previous researches, the literature review of this paper can be divided into following aspects: "green R \& D of supply chain" and "financing decision of supply chain." The latter could be further divided into "bank financing" and "trade credit financing."

Green supply chain management has been an active area of research in operations management, such as Beamon [13], Murali et al. [14], Wang et al. [15], and Zhang et al. [16]. Despite the high additional cost of green $\mathrm{R} \& \mathrm{D}$, many literatures are unfolded under the assumption of sufficient capital. For example, Zhu and He [17] compared two green R \& D strategies under sufficient capital; one is the development-intensive green product, the other is the marginalcost-intensive green product. Yenipazarli [18] confirmed that green $\mathrm{R} \& \mathrm{D}$ exhibits diminishing returns for $\mathrm{R} \& \mathrm{D}$ efforts. To optimize returns, Jiang and Chen [19], considering consumer preference and green investment, discussed the optimal green R \& D strategy. In fact, the capital of enterprises is not always sufficient to support enterprises to invest in $\mathrm{R} \& \mathrm{D}$. To alleviate the $\mathrm{R} \& \mathrm{D}$ cost pressure, Gao et al. [20] and Wong et al. [15] explored the methods that can not only protect the ecological environment but also limit production cost rise. Similarly, Taleizadeh et al. [21] found that the green-cost-sharing contract between supply chain members can control the cost. The above research provides a way to solve the capital constraints from the perspective of contract. Different from the above research, this paper cancels the assumption of sufficient capital and solves the capital-constrained problem through financing.

Considering previous financing studies, the main studies related to our work are bank financing and trade credit financing. Bank financing is the main channel of supply chain members financing [6]. In this area, Cao and Yu [22] studied the problem that capital-constrained manufacturers obtain pledge loans by utilizing carbon emission permits. Wu et al. [23] constructed a mathematical model, and found that bank financing can solve the problem of capital constraints to a certain extent. Tao et al. [11] conformed that SMEs and banks can achieve a win-win situation as more good SMEs choose bank financing. Conversely, $\mathrm{Yu}$ and Rehman Khan [24] pointed out that bank financing is not the best way because SMEs cannot afford the high interest rate of banks. For other available financing channels, some scholars pay attention to trade credit financing in operation management: for example, Haley and Higgins [25], Seifertet et al. [26], etc. These literatures proved that trade credit is an 
effective financing channel, especially for SMEs. Similarly, Wang et al. [27] and Ma et al. [28] also proved that enterprises cooperate with each other in supply chain financing, which can improve interests of both parties at the same time. In summary, existing studies have extensively confirmed that supply chain financing plays an important role in supply chain management [29]. The above research mainly focuses on a single financing channel. When considering some available financing channels, the financing decision of enterprises is more worthy of attention.

This paper is closely related to the choice of financing channels when enterprises are facing multiple available financing channels. Some works compared bank financing and trade credit financing when retailers are under capital constraints $[4,30]$. In the green supply chain, $\mathrm{Wu}$ et al. [31] discussed the impact of manufacturer carbon emission reduction on the optimal ordering of capital-constrained retailer under bank financing and trade credit financing. The literatures mentioned above pay more attention to retailers' financing. As for manufacturers' financing, Huang et al. [32] explored green credit, manufacturer subsidy, and sales subsidy, and proved that green credit (GC) can bring the highest benefits of social welfare and environmental protection. Cao and $\mathrm{Yu}$ [7] studied the financing equilibrium of green credit financing and mixed financing. Considering the uncertainty of market demand and consumers' low-carbon preference, Cao et al. [12] further studied the optimal procurement issues of capital-constrained manufacturer under two financing channels.

In the aforementioned literature, besides subsidy research [32], a common assumption is that green $R$ \& D capital of manufacturers is sufficient. Moreover, the researches on financing mainly study the ordering and inventory problems of capital-constrained supply chain. While the insights gained from these works are valuable, they do not address green $\mathrm{R} \& \mathrm{D}$ financing of manufacturers commonly observed in practice. Therefore, we inject more realism by considering a manufacturer whose green $\mathrm{R} \& \mathrm{D}$ capital is capital-constrained, and answer the practical question as to how manufacturer initial capital affects operational and financing decisions. In summary, this paper analyzes three scenarios of green supply chain: no financing, bank financing, and trade credit financing, by the proposed game model.

\section{Problem Description and Basic Assumptions}

This paper takes a typical supply chain with a manufacturer $M$ and a retailer $R$ as the research objects. Among them, the manufacturer is the leader, and the retailer is the follower. Facing an increasing environmental awareness of consumers, manufacturers enhance the product green degree by green R \& D to meet consumers' green demand. Taking automobile industry as example, products' green degree can refer to the emission reduction level or energy saving level of automobiles. In the process of the Stackelberg game, the manufacturer first decides the wholesale price $w$ and products' green degree $g$, then the retailer follows by setting the retailer price $p$. Due to the increasing marginal cost, the $\mathrm{R} \& \mathrm{D}$ cost of manufacturers will increase rapidly with the improvement of product green degree. Hence, referring to Zhu and He [17], Jiang and Chen [19], this paper assumes that the green $\mathrm{R} \& \mathrm{D}$ cost of manufacturers is a function of products' green degree $g: \mathrm{kg}^{2} / 2$, where $k(k>0)$ is the green $\mathrm{R} \& \mathrm{D}$ cost coefficient. Furthermore, since the green R \& D cost of manufacturers belongs to one-time capital investment, the green $\mathrm{R} \& \mathrm{D}$ of manufacturers will not affect products' unit cost $c(c>0)$, and $c<w<p$.

When the manufacturer's initial capital $F(F \geq 0)$ cannot support the optimal green $\mathrm{R} \& \mathrm{D}$, the decision of the manufacturer is constrained by the initial capital, while the retailer's decision is only indirectly affected by the game process. The manufacturer obtains the remaining capital $L=$ $\mathrm{kg}^{2} / 2-F$ through two available financing channels: bank and trade credit. This paper assumes that the output of R \& D is certain, that is, there is no risk of $\mathrm{R} \& \mathrm{D}$ failure. To simplify the explanation, the superscripts $B, T, N$ are used to indicate bank financing, trade credit financing, and no financing, and the subscripts $M, R$ are used to indicate the manufacturer and retailer.

In this paper, the demand of the manufacturer is consistent with that of the retailer. According to the description of green product demand in Zhu and He [17], the products' demand is set as $D=\alpha-\beta p+\gamma g$. Among them, $\alpha(\alpha>0)$ is the total market demand potential, $\beta(\beta>0)$ is the consumer price sensitivity, and $\gamma(\gamma>0)$ is the consumers' preference for green products. That is, the market demand for green products is negatively correlated with price $p$, and positively correlated with products' green degree $g$.

\section{Model}

4.1. Basic Model. This subsection constructs the green supply chain operation decision-making model when no financing channel is viable and it is taken as the basic model for subsequent analysis.

We suppose that the manufacturers' capital is not enough to invest in the optimal R \& $\mathrm{D}$ investment. According to Zhu and He [17], the optimal R \& D investment of the manufacturer with sufficient capital is $F^{N}=\left(k \gamma^{2}(\alpha-\beta c)^{2} / 2\left(4 \beta k-\gamma^{2}\right)^{2}\right)$. When no viable financing channels are available, the manufacturer can only determine the produce green degree and wholesale price under its initial capital. Sequentially, the retailer decides the optimal retail price according to the wholesale price and the produce green degree. In this scenario, both the manufacturer and retailer are rational and take profit maximization as decision-making objectives:

$$
\begin{aligned}
& \begin{cases}\operatorname{Max} & \pi_{M}^{N}=(w-c)(\alpha-\beta p+\gamma g)-\frac{1}{2} k g^{2} \\
\text { s.t. } & \frac{1}{2} k g^{2} \leq F,\end{cases} \\
& \operatorname{Max} \pi_{R}^{N}=(p-w)(\alpha-\beta p+\gamma g),
\end{aligned}
$$


Proposition 1. When no financing channels are available, the optimal products green degree $g^{N *}$, wholesale price $w^{N *}$, and retail price $p^{N *}$ are, respectively

$$
\begin{aligned}
& g^{N *}= \begin{cases}\frac{\gamma(\alpha-\beta c)}{4 \beta k-\gamma^{2}}, & F \geq F^{N}, \\
\sqrt{\frac{2 F}{k}}, \quad F<F^{N},\end{cases} \\
& w^{N *}= \begin{cases}\frac{2 k(\alpha+\beta c)-c \gamma^{2}}{4 \beta k-\gamma^{2}}, & F \geq F^{N}, \\
\frac{\alpha+\beta c}{2 \beta}+\frac{\gamma}{2 \beta} \sqrt{\frac{2 F}{k}}, & F<F^{N},\end{cases} \\
& p^{N *}= \begin{cases}\frac{3 \alpha k+\beta c k-c \gamma^{2}}{4 \beta k-\gamma^{2}}, & F \geq F^{N}, \\
\frac{3 \alpha+\beta c}{4 \beta}+\frac{3 \gamma}{4 \beta} \sqrt{\frac{2 F}{k}}, & F<F^{N},\end{cases}
\end{aligned}
$$

where $F^{N}=\left(k \gamma^{2}(\alpha-\beta c)^{2} / 2\left(4 \beta k-\gamma^{2}\right)^{2}\right)$.

All proofs are presented in Appendix.

Proposition 2. When no financing channels are available, the products demand $D^{N *}$, manufacturer's optimal profit $\pi_{M}^{N *}$, and retailer's optimal profit $\pi_{R}^{N *}$ are, respectively,

$$
\begin{aligned}
& D^{N *}= \begin{cases}\frac{\beta k(\alpha-\beta c)}{4 \beta k-\gamma^{2}}, & F \geq F^{N}, \\
\frac{\alpha-\beta c+\gamma \sqrt{2 F / k}}{4}, & F<F^{N},\end{cases} \\
& \pi_{M}^{N *}= \begin{cases}\frac{k(\alpha-\beta c)^{2}}{2\left(4 \beta k-\gamma^{2}\right)}, & F \geq F^{N}, \\
\frac{(\alpha-\beta c+\gamma \sqrt{2 F / k})^{2}}{8 \beta}-F, & F<F^{N},\end{cases} \\
& \pi_{R}^{N *}= \begin{cases}\frac{\beta k^{2}(\alpha-\beta c)^{2}}{\left(4 \beta k-\gamma^{2}\right)^{2}}, & F \geq F^{N}, \\
\frac{1}{16 \beta}\left(\alpha-\beta c+\gamma \sqrt{\frac{2 F}{k}}\right)^{2}, & F<F^{N} .\end{cases}
\end{aligned}
$$

4.2. Bank Financing Channel. When the manufacturer's initial capital is $F<F^{N}$, the manufacturer chooses bank financing to obtain the required financial support. As shown in Figure 1, the bank acts as the capital provider. At the beginning, based on manufacturer's fixed assets, the bank provides the manufacturer the needed capital at the interest

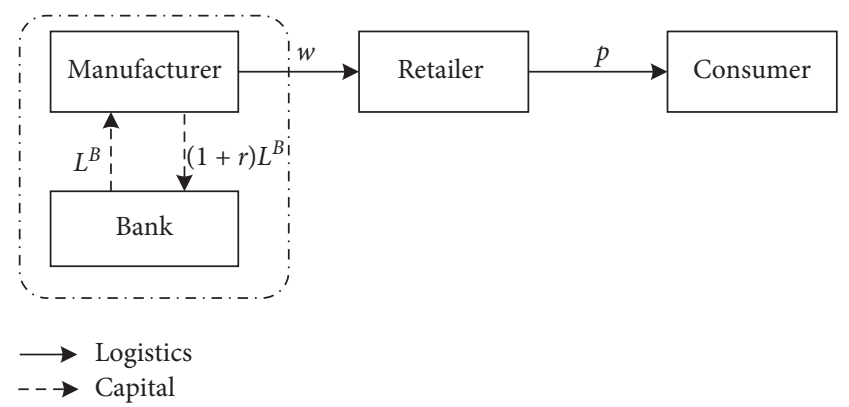

FIgURE 1: Supply chain operation and financing process under bank financing channel.

rate $r$. Then, the capital-constrained manufacturer determines the product green degree $g$, wholesale price $w$, and the financing scale $L^{B}\left(L^{B}=(1 / 2) \mathrm{kg}^{2}-F\right)$. Finally, the retailer provides green products to consumers at retail price $p$ and the manufacturer repays the loan and interest $(1+r) L^{B}$ to the bank. Both the manufacturer and retailer make decisions to maximize profits $\pi_{M}^{B}$ and $\pi_{R}^{B}$ :

$\begin{cases}\operatorname{Max} & \pi_{M}^{B}=(w-c) D-(1+r) L^{B}-F=(w-c) D-r L^{B}-\frac{1}{2} k g^{2} \\ \text { s.t. } & F<F^{N},\end{cases}$

$\operatorname{Max} \pi_{R}^{B}=(p-w)(\alpha-\beta p+\gamma g)$.

Proposition 3. Under the bank financing channel, the products' optimal green degree $g^{B *}$, wholesale price $w^{B *}$, and retail price $p^{B *}$ are, respectively,

$$
\begin{aligned}
& g^{B *}= \begin{cases}\sqrt{\frac{2 F}{k}}, & F \geq F^{B}, \\
\frac{(\alpha-\beta c) \gamma}{4 \beta k(1+r)-\gamma^{2}}, & F<F^{B},\end{cases} \\
& w^{B *}= \begin{cases}\frac{\alpha+\beta c}{2 \beta}+\frac{\gamma}{2 \beta} \sqrt{\frac{2 F}{k}}, & F \geq F^{B}, \\
\frac{2 k(\alpha+\beta c)(1+r)-c \gamma^{2}}{4 \beta k(1+r)-\gamma^{2}}, & F<F^{B},\end{cases} \\
& p^{B *}= \begin{cases}\frac{3 \alpha+\beta c}{4 \beta}+\frac{3 \gamma}{4 \beta} \sqrt{\frac{2 F}{k}}, & F \geq F^{B}, \\
\frac{k(3 \alpha+\beta c)(1+r)-c \gamma^{2}}{4 \beta k(1+r)-\gamma^{2}}, & F<F^{B},\end{cases}
\end{aligned}
$$

where $F^{B}=\left(k \gamma^{2}(\alpha-\beta c)^{2} / 2\left[4 \beta k(1+r)-\gamma^{2}\right]^{2}\right)$.

Corollary 1. When $0<F<F^{B}$, the products' optimal green degree $g^{B *}$, wholesale price $w^{B *}$, and retail price $p^{B *}$ are positively correlated with the consumers' green sensitivity $\gamma$, 
and negatively correlated with the green cost coefficient $k$ and bank interest rate $r$.

Consumers with higher green preference pay more attention to the products' green degree and tend to pay higher prices. However, the higher $\mathrm{R} \& \mathrm{D}$ cost coefficient and financing cost restrain the manufacturer's willingness to invest in $\mathrm{R} \& \mathrm{D}$. Hence, faced with the higher green preference, the lower $\mathrm{R} \& \mathrm{D}$ cost, and bank loan interest rate, the manufacturer can benefit from increasing green $R$ \& $D$ investment. Meanwhile, with the increase in R \& D costs, manufacturers transfer part $\mathrm{R} \& \mathrm{D}$ costs to retailers by increasing the wholesale price, which sequentially leads to the rise of retail prices.

Proposition 4. Under the bank financing channel, the product demand $D^{B *}$, manufacturer's financing scale $L^{B *}$, retailer's optimal profit $\pi_{R}^{B *}$, and manufacturer's optimal profit $\pi_{M}^{B *}$ are, respectively,

$$
\begin{aligned}
& D^{B *}= \begin{cases}\frac{\alpha-\beta c+\gamma \sqrt{2 F / k}}{4}, & F^{B} \leq F<F^{N}, \\
\frac{\beta k(1+r)(\alpha-\beta c)}{4 \beta k+4 b k r-\gamma^{2}}, & 0 \leq F<F^{B},\end{cases} \\
& L^{B *}= \begin{cases}0, & F^{B} \leq F<F^{N}, \\
\frac{k \gamma^{2}(\alpha-\beta c)^{2}}{2\left[4 \beta k(1+r)-\gamma^{2}\right]^{2}}-F, & 0 \leq F<F^{B},\end{cases} \\
& \pi_{R}^{B *}= \begin{cases}\frac{1}{16 \beta}\left(\alpha-\beta c+\gamma \sqrt{\frac{2 F}{k}}\right)^{2}, & F^{B} \leq F<F^{N}, \\
\frac{\beta k^{2}(\alpha-\beta c)^{2}(1+r)^{2}}{4 \beta k r+4 \beta k-\gamma^{2}}, & 0 \leq F<F^{B},\end{cases} \\
& \pi_{M}^{B *}= \begin{cases}\frac{(\alpha-\beta c+\gamma \sqrt{2 F / k})^{2}}{8 \beta}-F, & F^{B} \leq F<F^{N}, \\
\frac{k(\alpha-\beta c)^{2}(1+r)+2 F r\left[4 k \beta(1+r)-\gamma^{2}\right]}{2\left[4 k \beta(1+r)-\gamma^{2}\right]}, & 0 \leq F<F^{B} .\end{cases}
\end{aligned}
$$

To ensure that the results are meaningful, manufacturer's financing scale should be nonnegative. From the above equilibrium decisions, we can obtain that manufacturer will choose bank financing when $F \leq F^{B}=\left(k \gamma^{2}(\alpha-\beta c)^{2}\right.$ / $\left.2\left[4 \beta k(1+r)-\gamma^{2}\right]^{2}\right)$, which indicates that manufacturer's initial capital is a crucial factor affecting manufacturer financing strategy.

Corollary 2. When $0<F<F^{B}$, the optimal financing scale $L^{B *}$ of the manufacturer is positively correlated with consumers' green preference $\gamma$, and negatively correlated with green cost coefficient $k$ and bank interest rate $r$.

Corollary 2 shows that when manufacturer's initial capital is fixed, the manufacturer's optimal financing scale increases as consumers' green preference increases but decreases as the green cost coefficient and bank loan interest rate increase. This is because the higher consumers' green preference urges manufacturers to improve the products' green degree to meet consumers' preference. Similarly, lower
R \& D cost and bank interest rate enable manufacturers to obtain greater benefits from expanding green R \& D. Hence, with the increase of consumer preference, and the decrease of R \& D cost and interest rate, the manufacturer will expand the financing scale to implement greener R \& D investment, and then achieve greater profit.

Corollary 3. When $0<F<F^{B}$, the manufacturer's optimal profit $\pi_{M}^{B *}$ is positively correlated with its initial capital $F$, while the retailer's optimal profit $\pi_{R}^{B *}$ is irrelevant to the initial capital F.

From the above corollary, it is worth noting that the profitability of the manufacturer is closely related to its initial capital level and the retailer's profit is not affected. Obviously, the higher the manufacturer's initial capital, the smaller the required financing scale and the lower the financing cost under the same green $\mathrm{R} \& \mathrm{D}$ investment. Hence, manufacturer's profit increases accordingly. However, the result about the retailer seems counter-intuitive. In 
fact, it is the result of the game between the manufacturer and retailer. Because in the Stackelberg game, the manufacturer is the leader and has the decision-making advantage. The manufacturer can transfer the corresponding financing costs by increasing the wholesale price to maximize profit. Similarly, the retailer is also not willing to bear the extra cost. Hence, the result of the game between the manufacturer and the retailer is that the retailer cannot get extra profit. For this reason, retailer's profit change is determined, and it has no direct relationship with manufacturer's initial capital under bank financing.

4.3. Trade Credit Financing Channel. When manufacturer's initial capital is $F<F^{N}$, the manufacturer will finance from the trade credit channel. As shown in Figure 2, the retailer acts as capital provider, and gains early payment discounts $\theta(0<\theta<1)$ as a return on cooperation. The manufacturer determines the products' green degree $g$ and wholesale price $w$. The retailer provides the manufacturer the required capital $L^{T}=\mathrm{kg}^{2} / 2-F$ in the form of advance payment. After production, the manufacturer needs to deliver products $L^{T} /[(1-\theta) w]$ to the retailer because of the retailer's advance payment. Then, the remaining products are offered to the retailer at the wholesale price $w$. Ultimately, the retailer provides all green products to consumers at retail price $p$. Both the manufacturer and the retailer make decisions to maximize profits $\pi_{M}^{T}$ and $\pi_{R}^{T}$.

$$
\begin{aligned}
& \begin{cases}\operatorname{Max} & \pi_{M}^{T}=(w-c)\left[D-\frac{L^{T}}{(1-\theta) w}\right]+\left[\left(\frac{1}{2} k g^{2}-F\right)-c \frac{L^{T}}{(1-\theta) w}\right]-\frac{1}{2} k g^{2} \\
\text { s.t. } & F<F^{N}\end{cases} \\
& \operatorname{Max} \pi_{R}^{T}=(p-w)\left[D-\frac{L^{T}}{(1-\theta) w}\right]+\left[-p \frac{L^{T}}{(1-\theta) w}\right]-\left(\frac{1}{2} k g^{2}-F\right) .
\end{aligned}
$$

Proposition 5. Under the trade credit financing channel, the optimal products' green degree $g^{T *}$, wholesale price $w^{T *}$, and retail price $p^{T *}$, respectively, are

$$
\begin{aligned}
& g^{T *}= \begin{cases}\sqrt{\frac{2 F}{k}}, & F \geq F^{T}, \\
\frac{(1-\theta)(\alpha-\beta c) \gamma}{4 \beta k-(1-\theta) \gamma^{2}}, & F<F^{T},\end{cases} \\
& w^{T *}= \begin{cases}\frac{\alpha+\beta c}{2 \beta}+\frac{\gamma}{2 \beta} \sqrt{\frac{2 F}{k}}, & F \geq F^{T}, \\
\frac{2 k(\alpha+\beta c)-(1-\theta) c \gamma^{2}}{4 \beta k-(1-\theta) \gamma^{2}}, & F<F^{T},\end{cases} \\
& p^{T *}= \begin{cases}\frac{3 \alpha+\beta c}{4 \beta}+\frac{3 \gamma}{4 \beta} \sqrt{\frac{2 F}{k}}, & F \geq F^{T}, \\
\frac{k(3 \alpha+\beta c)-(1-\theta) c \gamma^{2}}{4 \beta k-(1-\theta) \gamma^{2}}, & F<F^{T},\end{cases}
\end{aligned}
$$

where $F^{T}=\left(k \gamma^{2}(1-\theta)^{2}(\alpha-\beta c)^{2} / 2\left[4 \beta k-(1-\theta) \gamma^{2}\right]^{2}\right)$.

Corollary 4. When $0<F<F^{T}$, the optimal green degree $g^{T *}$, wholesale price $w^{T *}$, and retail price $p^{T *}$ are positively correlated with consumers' green preference coefficient $\gamma$, and negatively correlated with green cost coefficient $k$ and early payment discounts rate $\theta$.

Corollary 4 is consistent with Corollary 1; the optimal green degree, wholesale price, and retail price of products increase with the increase of green preference of consumers but decrease with the increase of $R \& D$ cost coefficient and early payment discounts rate. The result indicates that the relationship between the optimal decision of supply chain and the green preference of consumers and the cost of R \& D is not affected by the financing channel.

Proposition 6. Under the trade credit financing channel, the product's demand $D^{T *}$, manufacturer's financing scale $L^{T *}$, and optimal profit $\pi_{M}^{T *}$, as well as retailer's optimal profit $\pi_{R}^{T *}$, respectively, are 


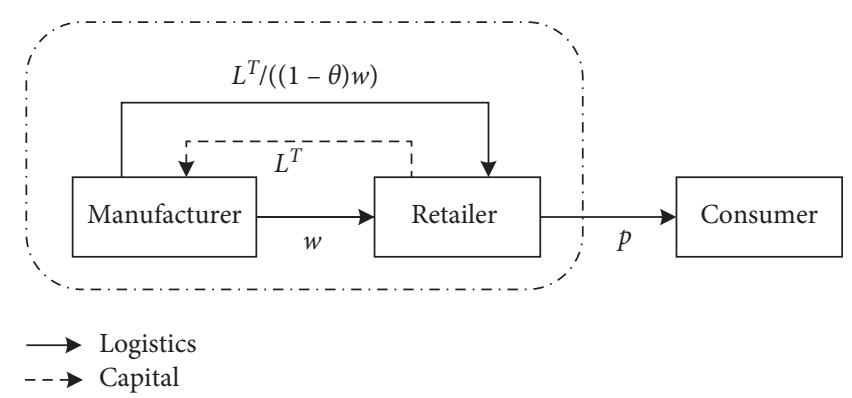

FIGURE 2: Supply chain operation and financing process under trade credit financing channel.

$D^{T *}= \begin{cases}\frac{\alpha-\beta c+\gamma \sqrt{2 F / k}}{4}, & F^{T} \leq F<F^{N}, \\ \frac{k \beta(\alpha-\beta c)}{4 \beta k-(1-\theta) \gamma^{2}}, & 0 \leq F<F^{T}\end{cases}$

$L^{T *}= \begin{cases}0, & F^{T} \leq F<F^{N}, \\ \frac{k \gamma^{2}(1-\theta)^{2}(\alpha-\beta c)^{2}}{2\left[4 \beta k-(1-\theta) \gamma^{2}\right]^{2}}-F, & 0 \leq F<F^{T},\end{cases}$

$\pi_{M}^{T *}= \begin{cases}\frac{(\alpha-\beta c+\gamma \sqrt{2 F / k})^{2}}{8 \beta}-F, & F^{T} \leq F<F^{N}, \\ \frac{k(1-\theta)(\alpha-\beta c)^{2}+2 F \theta\left[4 k \beta-(1-\theta) \gamma^{2}\right]}{2(1-\theta)\left[4 \beta k-(1-\theta) \gamma^{2}\right]}, & 0 \leq F<F^{T},\end{cases}$

$$
\pi_{R}^{T *}= \begin{cases}\frac{1}{16 \beta}\left(\alpha-\beta c+\gamma \sqrt{\frac{2 F}{k}}\right)^{2}, & F^{T} \leq F<F^{N}, \\ \frac{2 F k^{2}(1-\theta)(\alpha-\beta c)^{2}+\theta k \gamma^{2}(1-\theta)^{2}(\alpha-\beta c)^{2}-2 \theta F\left[4 \beta k-(1-\theta) \gamma^{2}\right]^{2}}{2(1-\theta)\left[4 k \beta-(1-\theta) \gamma^{2}\right]^{2}}, & 0 \leq F<F^{T} .\end{cases}
$$

As the financing scale is nonnegative, the initial capital of manufacturers should meet the condition $F<F^{T}=\left(k \gamma^{2}(1-\theta)^{2}(\alpha-\beta c)^{2} / 2\left[4 \beta k-(1-\theta) \gamma^{2}\right]^{2}\right)$. The result is consistent with bank financing, this is, trade credit financing is not always dominant for the capital-constrained manufacturer. When manufacturer's initial capital meets certain conditions, advance payment by retailer is a better decision, which proves that the initial capital is a key factor that cannot be ignored, no matter which financing channel.

Corollary 5. When $0<F<F^{T}$, the optimal financing scale $L^{T *}$ of manufacturers is positively correlated with consumers' green preference $\gamma$, and negatively correlated with green cost coefficient $k$ and early payment discounts rate $\theta$.

Corollary 5 indicates that manufacturer's financing scale is affected by consumers' green preference, green cost coefficient, and early payment discounts rate. The results are reasonable. Smaller financing scale should be adopted if consumers' green preference is low or green cost coefficient and early payment discounts rate are high. Thus, for manufacturer financing, consumers' green preference is an incentive factor, while cost is a restraining factor, and no matter which financing channels are employed, the conclusion is always valid.

Corollary 6. When $0<F<F^{T}$, manufacturer's optimal profit $\pi_{M}^{T *}$ is positively correlated with its initial capital $F$, while the retailer's optimal profit $\pi_{R}^{T *}$ is negatively correlated with the initial capital $F$.

Corollary 6 demonstrates the effect of manufacturer's initial capital on the optimal profit of the manufacturer and retailer under the credit trade financing channel. Note that if the manufacturer possesses more initial capital, the smaller is the financing scale required under the same green $R$ \& D 
investment, and thereby the lower is the financing cost paid. Accordingly, the manufacturer's profit is improved. As for the retailer, the revenue from selling greener products is roughly balanced with the increased wholesale prices. However, with the increase of the initial capital, the manufacturer pays the retailer less financing cost, which leads to the increase of purchasing cost that the retailer needs to pay. Hence, retailer's profit decreases.

4.4. Comparative Analysis. As in the above analysis, when $F<F^{N}$, the manufacturer can obtain financial support through the bank or trade credit. However, faced with the two financing channels simultaneously, which financing channel is better, and how different financing channels affect supply chain operation decisions? These questions inspire us to detect; this subsection will further compare and analyze the supply chain operation decision and manufacturer profit under different financing channels, and search for the dominant financing channel of the manufacturer.

Corollary 7. When $\theta>r /(1+r)$, there is $F^{T}<F^{B}$; otherwise, $\theta \leq r /(1+r), F^{T} \geq F^{B}$.

Corollary 7 demonstrates the influence of the financing cost on the financing preference of the manufacturer. Compared with the trade credit financing channel, the manufacturer's financing willingness under the bank channel is higher when $\theta>r /(1+r)$; On the contrary, when $\theta \leq r /(1+r)$, the manufacturer prefers to choose trade credit financing channels. The implication of the result is interesting. Manufacturers whose capital is insufficient may be tempted to seek viable financing channels to increase R \& D investment. Besides, the financing willingness of manufacturers is closely related to the cost of different financing channels. That is, the lower financing cost not only reduces the cost but also promotes the manufacturer's financing willingness, which enlightens us that adjusting the financing environment can also effectively affect the greening process in the case of insufficient capital.

Corollary 8. $F<\min \left(F^{T}, F^{B}\right)$, when $\theta>r /(1+r)$, there are $g^{B *}>g^{T *}, w^{B *}>w^{T *}, p^{B *}>p^{T *}$. Conversely, $\theta \leq r /(1+r)$, there are $g^{B *} \leq g^{T *}, w^{B *} \leq w^{T *}, p^{B *} \leq p^{T *}$.

From the result, we know that the optimal decision of the green supply chain operation is closely related to $r$ and $\theta$ under the two financing channels. When $\theta>r /(1+r)$, compared with the trade credit, the manufacturer needs to pay lower financing costs under bank financing channels. According to Corollaries 1 and 4, we document that the product green degree is always negatively correlated with the $\mathrm{R} \& \mathrm{D}$ cost coefficient and financing cost. Hence, under the bank financing channel, the financing willingness of the manufacturer can be released more, and thereby the financing scale will be expanded to increase R \& D investment, and the corresponding product green degree will be improved. Simultaneously, with the increase of the R \& D cost, the manufacturer transfers part of the $\mathrm{R} \& \mathrm{D}$ cost to the retailer by increasing the wholesale price, which makes retail price rise accordingly. On the contrary, when $\theta \leq r /(1+r)$, the financing cost of the manufacturer under trade credit financing is smaller than bank financing, and then the financing willingness of the manufacturer is enhanced. Thus, under the trade credit financing channel, manufacturers will increase green $R$ \& D investment, and the green degree of products will be improved. Ultimately, wholesale and retail prices also rise.

Corollary 9. $F<\min \left(F^{T}, F^{B}\right)$, when $\theta>r /(1+r)$, there are $D^{B *}>D^{T *}, L^{B *}>L^{T *}, \pi_{M}^{B *}>\pi_{M}^{T *}$. Conversely $\theta \leq r /(1+r)$, there are $D^{B *} \leq D^{T *}, L^{B *} \leq L^{T *}, \pi_{M}^{B *} \leq \pi_{M}^{T *}$.

Corollary 9 shows that the relationship of the manufacturer's financing scale, market demand, and profit is closely related to bank interest rate and early payment discounts rate. From Corollary 8, we know that the green degree of products under the bank financing channel is higher than that of trade credit financing when $\theta>r /(1+r)$. Therefore, under the bank financing channel, manufacturers demand larger financing to support the increased R \& D investment when the initial capital is fixed, because the improvement of product green degree can better meet the green preference of consumers and stimulate greener consumption; then, the demand is increased. Hence, the improvement effect of manufacturer's profit under the bank financing channel is more significant in the case of $\theta>r /(1+r)$. On the contrary, $\theta \leq r /(1+r)$, compared with the bank financing channel, the financing cost under trade credit financing is more suitable for capitalconstrained manufacturer. In other words, the same financing cost makes the manufacturer benefit more from financing under the trade credit channel. Consequently, under the same level of initial capital, the manufacturer prefers trade credit financing to improve revenue.

\section{Numerical Analysis}

In order to further clarify the manufacturer's financing decision with capital constraints $F<F^{N}$, this section analyzes the impact of manufacturer's initial capital on manufacturer's and retailer's profits through numerical examples under different financing channels. Here, we refer to the numerical analysis method and parameter setting of existing research, such as Zhu and $\mathrm{He}$ [17], Su and $\mathrm{Li}$ [33], to verify the above conclusions. The optimal solution without capital constraint as a benchmark is denoted by superscript $S$, and the parameters are set as $\alpha=$ $2000 ; \beta=10 ; \gamma=7 ; c=2 ; k=500 ; r=0.1$, then $F^{N}=120$. Accordingly, the manufacturer's capital value range is less than 120 in the numerical analysis.

Figures 3(a) and 3(b) describe the change of the manufacturer's profit with initial capital under different financing strategies when $\theta=0.3$ and $\theta=0.03$ (i.e., $\theta>r /(1+r)$ and $\theta \leq r /(1+r))$. Figure 3 shows that when $F<\min \left(F^{T}, F^{B}\right)$, the manufacturer's profits are positively correlated with manufacturer's initial capital no matter which financing strategy, and with the increase of manufacturer's initial capital, financing is not always the dominant decision. This is, when $F<\max \left(F^{B}, F^{T}\right)$, manufacturers can improve their profits by financing through bank or trade credit; however, with the increase of initial capital 


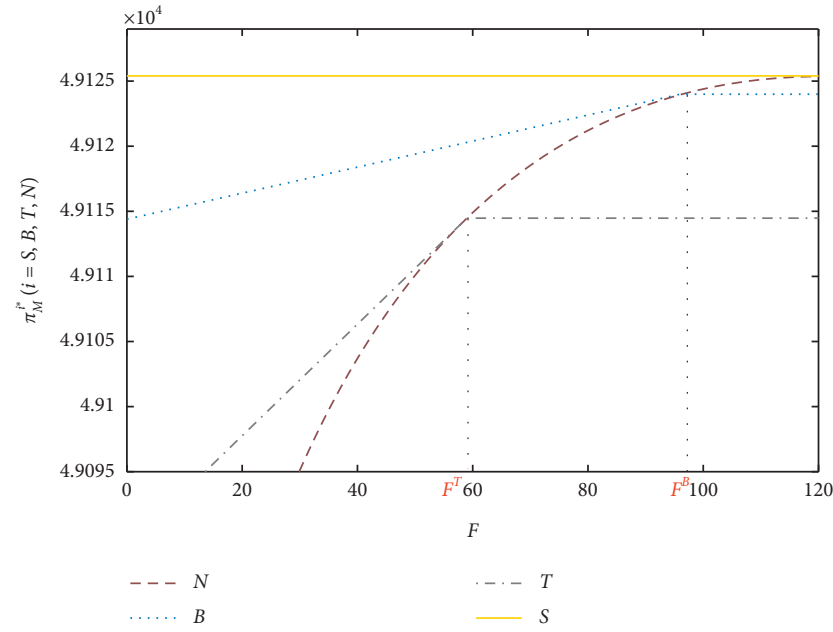

(a)

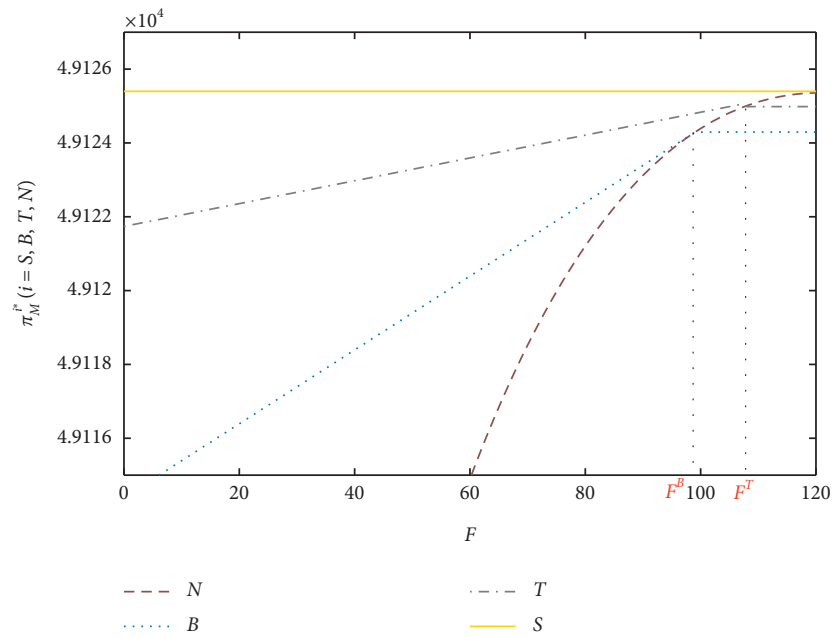

(b)

Figure 3: The influence of the initial capital on manufacturer's profit. (a) $\theta=0.3$. (b) $\theta=0.03$.

$\max \left(F^{B}, F^{T}\right)<F$, the profit without financing is better than the two financing channels. These results are consistent with Propositions 3 and 5, which indicate that the financing performance of manufacturers is closely related to initial capital, only under conditions $F<\max \left(F^{B}, F^{T}\right)$ can the manufacturer choose financing and improve profits.

In addition, comparing the manufacturer's optimal profit in four scenarios, we can get the optimal financing decision of the manufacturer with capital constraints. In Figure 3(a), $F^{T}<F^{B}$, the manufacturer chooses the bank financing first when the initial capital is lower than the financing threshold (i.e., $0<F<F^{B}$ ); with the improvement of initial capital, the manufacturer will not finance (i.e., $\left.F^{B}<F<F^{N}\right)$. However, in Figure 3(b), $F^{B}<F^{T}$, manufacturers merely prefer trade credit (i.e., $0<F<F^{T}$ ) or no financing (i.e., $F^{T}<F<F^{N}$ ). On the one hand, the higher initial capital reduces the financing cost; on the other hand, the lower financing cost encourages manufacturers to expand financing scale, which enables the manufacturer to further optimize R \& D investment and improve profits.

Figures 4(a) and 4(b) show the change of the retailer's profit with $F$ under different financing strategies when $\theta=$ 0.3 and $\theta=0.03$ (i.e., $\theta>r /(1+r)$ and $\theta \leq r /(1+r))$. It can be seen from Figure 4 that the retailer profit under the bank financing channel is independent of the manufacturer's capital level, which proves the conclusion of Corollary 3. Under the trade credit financing channel, the retailer's profit is always negatively correlated with manufacturer's initial capital which is consistent with Corollary 6; the reason is that the higher initial capital reduces the financing scale of the manufacturer, which leads to the increase of the retailer' $s$ purchasing costs, and accordingly, the retailers profit decrease.

Recalling the financing decision analyzed in Figure 3, we compare the profit, respectively, of the manufacturer and retailer in four situations. The results are interesting; the optimal profit of the retailer is roughly consistent with the manufacturer's financing preference in four cases. That is, when the manufacturer chooses the bank (i.e., $0<F<F^{B}$ ) or trade credit (i.e., $0<F<F^{T}$ ), the retailer's profit is better under the corresponding financing channel (see Figure 4); however, when manufacturers merely prefer no financing (i.e., $\max \left\{F^{B}, F^{T}\right\}<F<F^{N}$ ), retailer profits are not always optimal (see Figure 4(b)). Obviously, the profit of the retailer is higher when the retailer funds the manufacturer at a lower cost. The result indicates that the manufacturer and the retailer are a community of interests. In other words, the retailer has an intrinsic motivation to encourage the capitalconstrained manufacturer to expand the scale of trade credit with lower financing cost, which can achieve a win-win situation.

Compared with no financing, Figure $5(\theta=0.3$ and $\theta=0.03$ ) presents the impact of the initial capital on the profit change of the manufacturer and retailer when the manufacturer chooses bank financing or trade credit financing. Obviously, both financing channels can improve the manufacturer's income when the manufacturer's initial capital meets the condition $0<F<\min \left(F^{T}, F^{B}\right)$. However, no matter which financing channel is chosen, the retailer's profit improvement is more significant than that of the manufacturer under the corresponding financing channel. The profit growth of the retailer is the largest, especially under the trade credit financing channel. The manufacturer seeks financial support, but the retailer gains more. The lower financing cost can further release the manufacturer's $\mathrm{R}$ \& D willingness and produce products with higher green degree. Accordingly, retailers prefer making profits by selling products with higher green degree to meet the needs of consumers. Furthermore, under the trade credit financing channel, retailers can save part of the purchase cost. Here, the study further verifies again that the retailer has a strong internal motivation to support the manufacturer who is facing capital constraints. Hence, the retailer actively cooperates with the manufacturer on financing issues. 


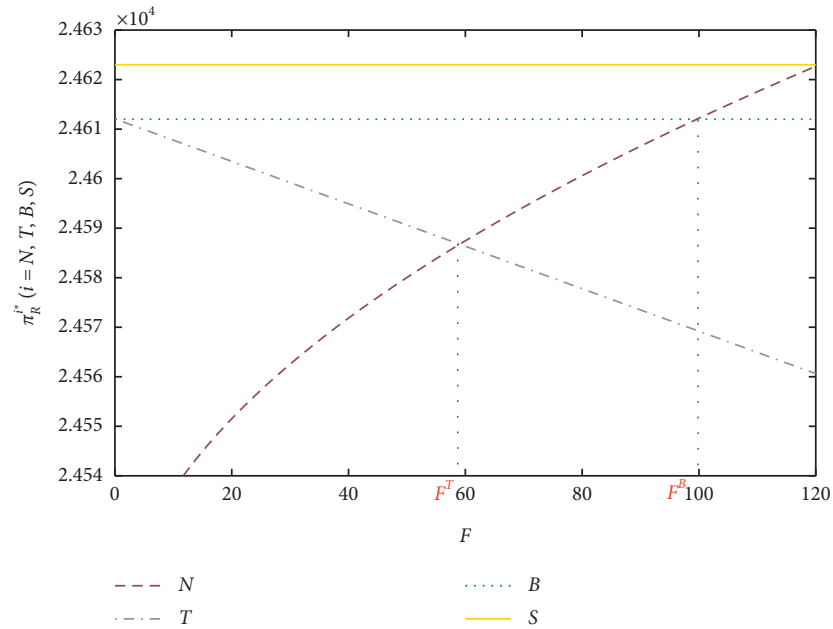

(a)

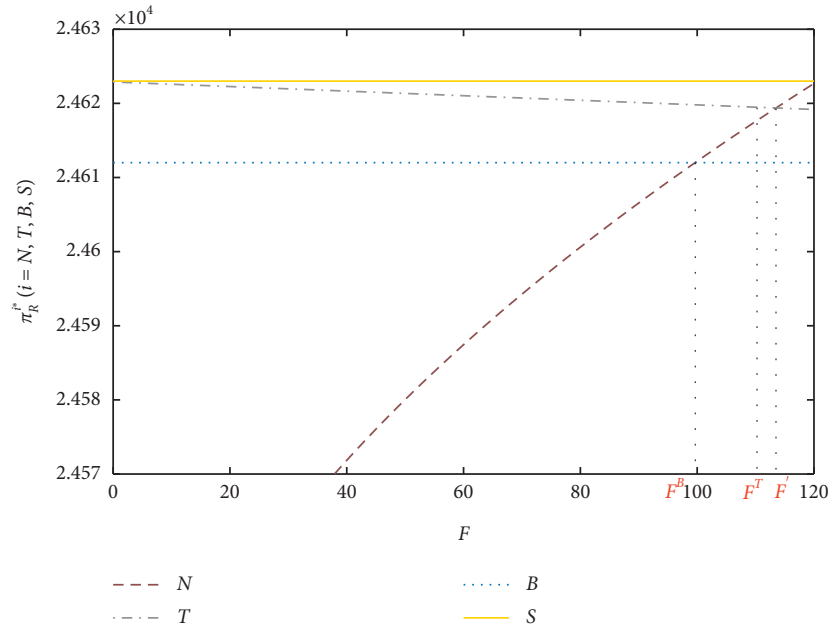

(b)

Figure 4: The influence of initial capital on the retailer's profit. (a) $\theta=0.3$. (b) $\theta=0.03$.

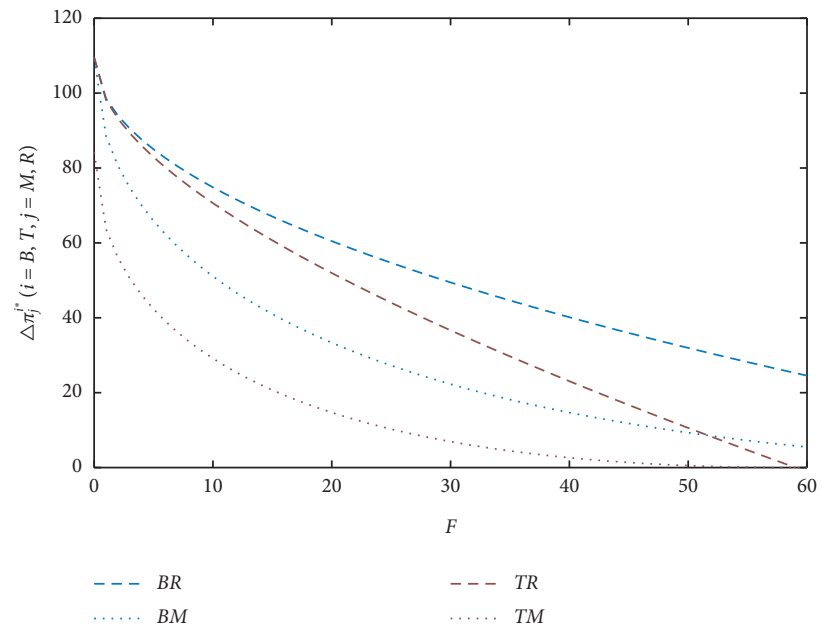

(a)

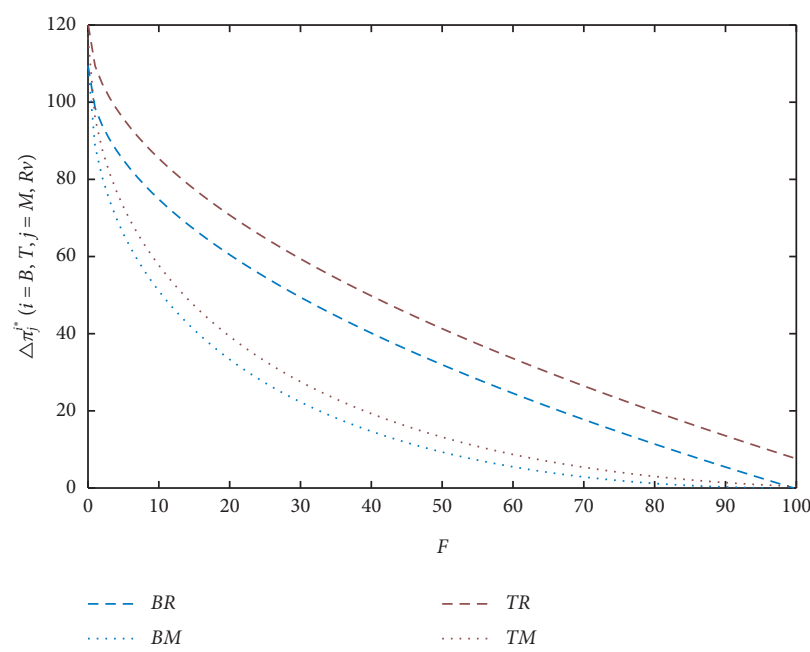

(b)

Figure 5: The influence of initial capital on the profit improvement of the manufacturer and retailer. (a) $\theta=0.3$. (b) $\theta=0.03$.

\section{Conclusion and Future Work}

To provide a reference for the green $\mathrm{R} \& \mathrm{D}$ decision of manufacturers who face initial capital constraint, this paper investigates the issue of the retailer and manufacturer's operating and financing decisions under capital constraints. Considering the manufacturer's initial capital, this paper constructs the Stackelberg game models in three scenarios: no financing, bank financing, and trade credit financing, and discusses the relationship between financing strategy and initial capital. Finally, this paper further analyzes the manufacturer's financing preference and the impact of different financing strategies on profits of the manufacturer and retailer, and then proves the importance of supply chain internal coordination from the perspective of supply chain financing. The main conclusions of the research are as follows:

Firstly, no matter which financing channel, financing is the optimal decision when manufacturer's initial capital is severely constrained. However, financing is not always dominant for the manufacturer with the increasing of the initial capital. That is, when the manufacturer's initial capital meets certain conditions, the manufacturer will no longer choose financing, which indicates that the financing decision is closely related to its initial capital.

Secondly, faced with the two financing channels of bank and trade credit, the manufacturer chooses bank's financing or trade credit financing entirely depending 
on the relationship of the bank interest rate and early payment discounts rate. What's more, the manufacturer has higher financing willingness under the preferred financing channel. From this, we can know that besides the green preference of consumers, financing factors can also affect the financing willingness of manufacturers.

Thirdly, no matter which financing strategy is adopted, the financing scale of manufacturers is positively correlated with consumers' green preference, and negatively correlated with green cost coefficient and financing cost. All these factors have a significant impact on the manufacturer's decision. Based on this, it provides a reference for controlling relevant variables and influencing the decisions of manufacturers with capital constraints

Finally, the retailer's optimal profit is roughly consistent with the manufacturer's preference in three scenarios. Moreover, the profit improvement of the retailer is always higher than that of the manufacturer, especially under the trade credit financing channel. In other words, compared with bank financing, when the retailer provides financing for the manufacturer in a dominant way, the win-win strategy of the manufacturer's profit and the retailer's profit can be realized at the same time.

The conclusions of this paper can be widely used in the manufacturing industry, such as automobile and household appliances, to provide support for the financing decisions of management. Based on our research, more general demand distribution functions can be studied in the future. Meanwhile, we just consider the situation of one manufacturer and one retailer, the competition among multiple supply chain members is worth considering. Besides, the influence of supply chain members' behavior on financing strategy of capital-constrained enterprises is also worth studying, such as fairness concerns.

\section{Appendix}

Proof of Proposition 1. This paper uses Backward Induction method to solve. Firstly, from equation (1), the second-order partial derivatives of $\pi_{R}^{N}$ with respect to $p$ can be obtained as $\left(\partial^{2} \pi_{R}^{N} / \partial p^{2}\right)=-2 \beta<0$. Thus, the retailer profit function $\pi_{R}^{N}$ has maximum value, and the optimal retailer price is given by $\left(\partial \pi_{R}^{N} / \partial p\right)=\alpha+g \gamma-2 \beta p+\beta w=0$.

To prove the joint concavity of $\pi_{M}^{N}$ on $w$ and $g$, we need to show that the Hessian matrix of $\pi_{M}^{N}(w, g)$ is negative ( semi ) definite, i.e., $\left(\partial^{2} \pi_{M}^{N} / \partial w^{2}\right)=-\beta<0,\left(\partial^{2} \pi_{M}^{N} / \partial g^{2}\right)=$ $-k<0$, and the determinant of the Hessian matrix is nonnegative. The Hessian matrix of $\pi_{M}^{N}(w, g)$ is

$$
H=\left[\begin{array}{cc}
\frac{\partial^{2} \pi_{M}^{N}}{\partial w^{2}} & \frac{\partial^{2} \pi_{M}^{N}}{\partial w \partial g} \\
\frac{\partial^{2} \pi_{M}^{N}}{\partial g \partial w} & \frac{\partial^{2} \pi_{M}^{N}}{\partial g^{2}}
\end{array}\right]=\left[\begin{array}{cc}
-\beta & \frac{\gamma}{2} \\
\frac{\gamma}{2} & -k
\end{array}\right] .
$$

Hence, $\operatorname{det}[H(w, g)]=\beta k-\left(\gamma^{2} / 4\right)$, if $\beta k-\left(\gamma^{2} / 4\right)>0$ are satisfied, $\operatorname{det}[H(w, g)] \geq 0$. Therefore, we take the firstorder derivative of $\pi_{M}^{T *}$ with respect to $g$ and $w$, then set them to be equal to zero $\left(\partial \pi_{M}^{N} / \partial g\right)=((w-c) \gamma / 2)-k g=0$ and $\left(\partial \pi_{M}^{N} / \partial w\right)=((\alpha+\beta c+\gamma g) / 2)-\beta w=0$ can be obtained. Solving two equations can provide the equilibrium result $g^{N *}=\left(\gamma(\alpha-\beta c) /\left(4 \beta k-\gamma^{2}\right)\right)$ and $w^{N *}=(2 k(\alpha+$ $\left.\beta c)-c \gamma^{2}\right) /\left(4 \beta k-\gamma^{2}\right)$. Substituting $g$ and $w$ into $p, p^{N *}=$ $\left(3 \alpha k+\beta c k-c \gamma^{2}\right) /\left(4 \beta k-\gamma^{2}\right)$ is proved. The optimal operation decisions without capital constraint have been proved.

When $F<F^{N}$, the manufacturer only invests in R\&D at their initial level, $g^{N *}=\sqrt{2 F / k}$, we prove that $\pi_{M}^{N}$ can get the maximum on $w$ for $\pi_{M}^{N}$ satisfy condition $\left(\partial^{2} \pi_{M}^{N}\right.$ l $\left.\partial w^{2}\right)=-\beta<0$. Hence, $w^{N *}=((\alpha+\beta c) / 2 \beta)+(\gamma / 2 \beta) \sqrt{2 F / k}$, $p^{N *}=((3 \alpha+\beta c) / 4 \beta)+(3 \gamma / 4 \beta) \sqrt{2 F / k}$.

Proof of Proposition 2. By substituting the equilibrium result of Proposition 1 into the equations (1) and (2), Proposition 2 can be obtained. Similarly, Propositions 4 and 6 can be proved.

Proof of Propositions 3 and 5. The proof is similar to that of Proposition 1, so we will not repeat it here.

Proof of Corollary 1. According to hypothesis $1 \alpha-\beta p>0$, $c<w<p$, hence $\alpha-\beta c>0$. 


$$
\begin{aligned}
& \frac{\partial g^{B *}}{\partial \gamma}=\frac{(\alpha-\beta c)\left[\gamma^{2}+4 \beta k(1+r)\right]}{\left[4 \beta k(1+r)-\gamma^{2}\right]^{2}}>0, \\
& \frac{\partial w^{B *}}{\partial \gamma}=\frac{4 \gamma k(1+r)(\alpha-\beta c)}{\left[4 \beta k(1+r)-\gamma^{2}\right]^{2}}>0, \\
& \frac{\partial p^{B *}}{\partial \gamma}=\frac{6 \gamma k(1+r)(\alpha-\beta c)}{\left[4 \beta k(1+r)-\gamma^{2}\right]^{2}}>0, \\
& \frac{\partial g^{B *}}{\partial k}=\frac{-4 \beta \gamma(1+r)(\alpha-\beta c)}{\left[4 \beta k(1+r)-\gamma^{2}\right]^{2}}<0, \\
& \frac{\partial w^{B *}}{\partial k}=\frac{-2 \beta \gamma^{2}(1+r)(\alpha-\beta c)}{\left[4 \beta k(1+r)-\gamma^{2}\right]^{2}}<0, \\
& \frac{\partial p^{B *}}{\partial k}=\frac{-3 \gamma^{2}(1+r)(\alpha-\beta c)}{\left[4 \beta k(1+r)-\gamma^{2}\right]^{2}}<0, \\
& \frac{\partial g^{B *}}{\partial r}=\frac{-2 \beta \gamma k(\alpha-\beta c)}{\left[4 \beta k(1+r)-\gamma^{2}\right]^{2}}<0, \\
& \frac{\partial w^{B *}}{\partial r}=\frac{-2 \gamma^{2} k(\alpha-\beta c)}{\left[4 \beta k(1+r)-\gamma^{2}\right]^{2}}<0, \\
& \frac{\partial p^{B *}}{\partial r}=\frac{-3 \gamma^{2} k(\alpha-\beta c)}{\left[4 \beta k(1+r)-\gamma^{2}\right]^{2}}<0 .
\end{aligned}
$$

The proof of Corollary 4 is similar to that of Corollary 1 , so here we will not repeat it.

Proof of Corollary 2. According to hypothesis $1 \alpha-\beta p>0$, $c<w<p$, hence $\alpha-\beta c>0$. Based on Proposition 4, when $F<F^{B}$, taking the first-order of $L^{B *}$ with respect to $\gamma, k$ and $r$ can be obtained as follows:

$$
\begin{aligned}
& \frac{\partial L^{B *}}{\partial \gamma}=\frac{\gamma k(\alpha-\beta c)^{2}\left[\gamma^{2}+4 \beta k(1+r)\right]}{\left[4 \beta k(1+r)-\gamma^{2}\right]^{3}}>0, \\
& \frac{\partial L^{B *}}{\partial k}=\frac{-k \gamma^{2}(\alpha-\beta c)^{2}\left[\gamma^{2}+4 \beta k(1+r)\right]}{\left[4 \beta k(1+r)-\gamma^{2}\right]^{3}}<0, \\
& \frac{\partial L^{B *}}{\partial r}=\frac{-4 \beta \gamma^{2} k^{2}(\alpha-\beta c)^{2}}{\left[4 \beta k(1+r)-\gamma^{2}\right]^{3}}<0 .
\end{aligned}
$$

Because of $\beta k-\left(\gamma^{2} / 4\right)>0$, therefore $\left(\partial L^{B *} / \partial \gamma\right)>0$, $\left(\partial L^{B *} / \partial k\right)<0$, and $\left(\partial L^{B *} / \partial r\right)<0$ hold. Corollary 2 is proved.

Proof of Corollary 3. Under the bank financing channel, based on the optimal profit of manufacturer and retailer of
Proposition 4, we can obtain that $\left(\partial \pi_{M}^{B *} / \partial F\right)=r>0$ and $\left(\partial \pi_{R}^{B *} / \partial F\right)=0$ hold. Thus, Corollary 3 holds.

Proof of Corollary 5. Based on Proposition 6, we take the first-order derivative of $L^{T *}$ and then obtain that

$$
\begin{aligned}
& \frac{\partial L^{T *}}{\partial \gamma}=\frac{\gamma k(1-\theta)^{2}(\alpha-\beta c)^{2}\left[4 \beta k+(1-\theta) \gamma^{2}\right]}{\left[4 \beta k-(1-\theta) \gamma^{2}\right]^{3}}>0, \\
& \frac{\partial L^{T *}}{\partial k}=\frac{-\gamma^{2}(1-\theta)^{2}(\alpha-\beta c)^{2}\left[4 \beta k+(1-\theta) \gamma^{2}\right]}{2\left[4 \beta k-(1-\theta) \gamma^{2}\right]^{3}}<0, \\
& \frac{\partial L^{T *}}{\partial \theta}=\frac{4(\theta-1) \beta \gamma^{2} k^{2}(\alpha-\beta c)^{2}}{\left[4 \beta k-(1-\theta) \gamma^{2}\right]^{3}}<0 .
\end{aligned}
$$

Hence, the relation between $L^{T *}$ and $\gamma, k, \theta$ can be obtained.

Proof of Corollary 6. Based on Proposition 6, we take the first-order derivative of $\pi_{M}^{T *}$ and $\pi_{R}^{T *}$, the result is that both $\left(\partial \pi_{M}^{T *} / \partial F\right)=\theta /(1-\theta)>0$ and $\left(\partial \pi_{R}^{T *} / \partial F\right)=\theta /(\theta-1)<0$ hold.

Proof of Corollary 7. When $F<\min \left(F^{T}, F^{B}\right)$, the threshold value of manufacturers in the bank financing channel and trade credit financing channel is,

$$
\begin{aligned}
& F^{T}=\frac{k \gamma^{2}(1-\theta)^{2}(\alpha-\beta c)^{2}}{2\left[4 \beta k-(1-\theta) \gamma^{2}\right]^{2}}=\frac{k \gamma^{2}(\alpha-\beta c)^{2}}{2\left[(4 \beta k /(1-\theta))-\gamma^{2}\right]^{2}}, \\
& F^{B}=\frac{k \gamma^{2}(\alpha-\beta c)^{2}}{2\left[4 \beta k(1+r)-\gamma^{2}\right]^{2}} .
\end{aligned}
$$

Building function $f(x)=\left(k \gamma^{2}(\alpha-\beta c)^{2} / 2\left[4 \beta k x-\gamma^{2}\right]^{2}\right)$, and $f^{\prime}(x)=-\left(4 \beta k^{2} \gamma^{2}(\alpha-\beta c)^{2} /\left[4 \beta k x-\gamma^{2}\right]^{3}\right)<0$; hence $f(x)$ is negatively correlated with $x$. When $1 /(1-\theta)>1+r$, Substitute into the function $f(x)$, we can obtain $f(1 /(1-\theta))<f(1+r)$. That is, $\theta>r /(1+r), \quad F^{T}<F^{B}$, $F<F^{T}$. Conversely $\theta \leq r /(1+r), \quad F^{T} \geq F^{B}$, then $F<F^{B}$. Hence Corollary 7 is proved.

Proof of Corollary 8. From Propositions 3 and 5, the optimal wholesale prices under bank and trade credit are

$$
\begin{aligned}
w^{B *} & =\frac{2 k(\alpha+\beta c)(1+r)-c \gamma^{2}}{4 \beta k(1+r)-\gamma^{2}} \\
& =\frac{2 k(\alpha+\beta c)-\left(c \gamma^{2} /(1+r)\right)}{4 \beta k-\left(\gamma^{2} /(1+r)\right)}, \\
w^{T *} & =\frac{2 k(\alpha+\beta c)-(1-\theta) c \gamma^{2}}{4 \beta k-(1-\theta) \gamma^{2}},
\end{aligned}
$$

respectively. Set the function $f(x)=((2 k(\alpha+\beta c)-$ $\left.\left.c \gamma^{2} x\right) /\left(4 \beta k-\gamma^{2} x\right)\right)(0<x<1)$, and then take the first-order 
derivative $f^{\prime}(x)=\left(2 k \gamma^{2}(\alpha-\beta c) /\left(4 \beta k-\gamma^{2} x\right)^{2}\right)>0$; therefore, $f(x)$ is positively correlated with $x$.

When $1 /(1+r)>1-\theta$, in other words $\theta>r /(1+r)$, substituting them into function $f(x)$, we can obtain

$$
\frac{2 k(\alpha+\beta c)(1+r)-c \gamma^{2}}{4 \beta k(1+r)-\gamma^{2}}>\frac{2 k(\alpha+\beta c)-(1-\theta) c \gamma^{2}}{4 \beta k-(1-\theta) \gamma^{2}}
$$

that is, $w^{B *}>w^{T *}$. Using the same method $g^{B *}>g^{T *}, p^{B *}>p^{T *}$ can be proved. On the contrary, $\theta \leq r /(1+r), \quad g^{B *} \leq g^{T *}, w^{B *} \leq w^{T *}, p^{B *} \leq p^{T *}$ still holds. Corollary 8 is proved.

Proof of Corollary 9. From Propositions 4 and 6, the optimal profit of the manufacturer under bank financing and trade credit financing is

$$
\begin{aligned}
& \pi_{M}^{B *}=\frac{k(\alpha-\beta c)^{2}(1+r)+2 F r\left(4 k \beta(1+r)-\gamma^{2}\right)}{2\left[4 k \beta(1+r)-\gamma^{2}\right]}, \\
& \pi_{M}^{T *}=\frac{k(1-\theta)(\alpha-\beta c)^{2}+2 F \theta\left[4 k \beta-(1-\theta) \gamma^{2}\right]}{2(1-\theta)\left[4 \beta k-(1-\theta) \gamma^{2}\right]},
\end{aligned}
$$

respectively. We set function

$$
\begin{aligned}
v(\theta)= & \pi_{M}^{B *}-\pi_{M}^{T *} \\
= & \frac{k(\alpha-\beta c)^{2}}{2}\left(\frac{1}{4 k \beta-\left(\gamma^{2} /(1+r)\right)}-\frac{1}{4 k \beta-(1-\theta) \gamma^{2}}\right) \\
& +F\left(r-\frac{\theta}{1-\theta}\right)
\end{aligned}
$$

and when $\theta=r /(1+r)$, substitute into function $v(\theta)$, $v(r /(1+r))=0$ holds. The first-order derivative $v^{\prime}(\theta)=\left(k \gamma^{2}(\alpha-\beta c)^{2} / 2\left[4 \beta k-(1-\theta) \gamma^{2}\right]^{2}\right)-\left(F /(1-\theta)^{2}\right)$. From Proof of Corollary 7, we know when $\theta>r /(1+r)$, $F<F^{T}$, and $\left(k \gamma^{2}(\alpha-\beta c)^{2} / 2\left[4 \beta k-(1-\theta) \gamma^{2}\right]^{2}\right)-\left(F^{T} /\right.$ $\left.(1-\theta)^{2}\right)=0$.

Therefore, we get

$$
\begin{aligned}
v^{\prime}(\theta) & =\frac{k \gamma^{2}(\alpha-\beta c)^{2}}{2\left[4 \beta k-(1-\theta) \gamma^{2}\right]^{2}}-\frac{F}{(1-\theta)^{2}} \\
& >\frac{k \gamma^{2}(\alpha-\beta c)^{2}}{2\left[4 \beta k-(1-\theta) \gamma^{2}\right]^{2}}-\frac{F^{T}}{(1-\theta)^{2}}=0,
\end{aligned}
$$

$v$ is positively correlated with $\theta$. Hence, when $\theta \leq r /(1+r)$, we get $v(\theta) \leq 0$, here $\pi_{M}^{B *} \leq \pi_{M}^{T *}$. With the increase of $\theta$, when $\theta>r /(1+r), v(\theta)>0$; that is $\pi_{M}^{B *}>\pi_{M}^{T *}$. The proof of $D^{B *} \leq D^{T *}, L^{B *} \leq L^{T *}$ and $D^{B *}>D^{T *}, L^{B *}>L^{T *}$ is similar to Corollaries 8 and 9 is proved.

\section{Data Availability}

All the data come from simulation analysis and no real data are adopted in this paper.

\section{Conflicts of Interest}

The authors declare that they have no conflicts of interest.

\section{Acknowledgments}

This work was supported by the National Natural Science Foundation of China under Grant No. 71771041.

\section{References}

[1] Z. Liu, T. D. Anderson, and J. M. Cruz, "Consumer environmental awareness and competition in two-stage supply chains," European Journal of Operational Research, vol. 218, no. 3, pp. 602-613, 2012.

[2] J. Kim and J. Rhee, "An empirical study on the impact of critical success factors on the balanced scorecard performance in Korean green supply chain management enterprises," International Journal of Production Research, vol. 50, no. 9, pp. 2465-2483, 2012.

[3] Y. Su and Y.-Q. Yu, "Spatial agglomeration of new energy industries on the performance of regional pollution control through spatial econometric analysis," Science of the Total Environment, vol. 704, Article ID 135261, 2020.

[4] P. Kouvelis and W. Zhao, "Financing the newsvendor: supplier vs. bank, and the structure of optimal trade credit contracts," Operations Research, vol. 60, no. 3, pp. 566-580, 2012.

[5] B. Zhang, J. Bi, and B. Liu, "Drivers and barriers to engage enterprises in environmental management initiatives in Suzhou industrial park, China," Frontiers of Environmental Science \& Engineering in China, vol. 3, no. 2, pp. 210-220, 2009.

[6] S. Deng, K. Fu, J. Xu, and K. Zhu, "The supply chain effects of trade credit under uncertain demands," Omega, vol. 98, Article ID 102113, 2021.

[7] E. Cao and M. Yu, "Trade credit financing and coordination for an emission-dependent supply chain," Computers \& Industrial Engineering, vol. 119, pp. 50-62, 2018.

[8] L. Fang and $\mathrm{S}$. Xu, "Financing equilibrium in a green supply chain with capital constraint," Computers \& Industrial Engineering, vol. 143, Article ID 106390, 2020.

[9] J. Chen, Y.-W. Zhou, and Y. Zhong, "A pricing/ordering model for a dyadic supply chain with buyback guarantee financing and fairness concerns," International Journal of Production Research, vol. 55, no. 18, pp. 5287-5304, 2017.

[10] Z.-H. Cao and Z.-Q. Cai, "Channel selection strategy for a retailer with finance constraint in a supply chain based on complex network theory," Complexity, vol. 2020, Article ID 6231427, 10 pages, 2020.

[11] Z. Tao, X. Li, X. Liu, and N. Feng, "Analysis of signal game for supply chain finance (SCF) of MSEs and banks based on incomplete information model," Discrete Dynamics in Nature and Society, vol. 2019, Article ID 3646097, 6 pages, 2019.

[12] E. Cao, L. Du, and J. Ruan, "Financing preferences and performance for an emission-dependent supply chain: supplier vs. bank," International Journal of Production Economics, vol. 208, pp. 383-399, 2019.

[13] B. M. Beamon, "Designing the green supply chain," Logistics Information Management, vol. 12, no. 4, pp. 332-342, 1999.

[14] K. Murali, M. K. Lim, and N. C. Petruzzi, "The effects of ecolabels and environmental regulation on green product development," Manufacturing \& Service Operations Management, vol. 21, no. 3, pp. 519-535, 2019. 
[15] C. Wang, Q. Zhang, and W. Zhang, "Corporate social responsibility, green supply chain management and firm performance: the moderating role of big-data analytics capability," Research in Transportation Business \& Management, vol. 37, Article ID 100557, 2020.

[16] W. Zhang, M. Zhang, W. Zhang, Q. Zhou, and X. Zhang, "What influences the effectiveness of green logistics policies? a grounded theory analysis," Science of the Total Environment, vol. 714, Article ID 136731, 2020.

[17] W. Zhu and Y. He, "Green product design in supply chains under competition," European Journal of Operational Research, vol. 258, no. 1, pp. 165-180, 2017.

[18] A. Yenipazarli, "Incentives for environmental research and development: consumer preferences, competitive pressure and emissions taxation," European Journal of Operational Research, vol. 276, no. 2, pp. 757-769, 2019.

[19] W. Jiang and X. Chen, "Optimal strategies for low carbon supply chain with strategic customer behavior and green technology investment," Discrete Dynamics in Nature and Society, vol. 2016, Article ID 9645087, 13 pages, 2016.

[20] J. Gao, Z. Xiao, B. Cao, and Q. Chai, "Green supply chain planning considering consumer's transportation process," Transportation Research Part E: Logistics and Transportation Review, vol. 109, pp. 311-330, 2018.

[21] A. A. Taleizadeh, M. Noori-Daryan, and S. S. Sana, "Manufacturing and selling tactics for a green supply chain under a green cost sharing and a refund agreement," Journal of Modelling in Management, vol. 15, no. 4, pp. 1419-1450, 2020.

[22] E. Cao and M. Yu, "The bright side of carbon emission permits on supply chain financing and performance," Omega, vol. 88, pp. 24-39, 2019.

[23] T. Wu, L.-G. Zhang, and T. Ge, "Managing financing risk in capacity investment under green supply chain competition," Technological Forecasting and Social Change, vol. 143, pp. 37-44, 2019.

[24] Z. Yu and S. A. Rehman Khan, "Evolutionary game analysis of green agricultural product supply chain financing system: COVID-19 pandemic," International Journal of Logistics Research and Applications, pp. 1-21, 2021.

[25] C. W. Haley and R. C. Higgins, "Inventory policy and trade credit financing," Management Science, vol. 20, no. 4-part-i, pp. 464-471, 1973.

[26] D. Seifert, R. W. Seifert, and M. Protopappa-Sieke, “A review of trade credit literature: opportunities for research in operations," European Journal of Operational Research, vol. 231, no. 2, pp. 245-256, 2013.

[27] Z. Wang, Q. Wang, Y. Lai, and C. Liang, "Drivers and outcomes of supply chain finance adoption: an empirical investigation in China," International Journal of Production Economics, vol. 220, Article ID 107453, 2020.

[28] H.-L. Ma, Z. X. Wang, and F. T. S. Chan, "How important are supply chain collaborative factors in supply chain finance? a view of financial service providers in China," International Journal of Production Economics, vol. 219, pp. 341-346, 2020.

[29] T. N. Bui, "Supply chain finance, financial development and profitability of real estate firms in Vietnam," Uncertain Supply Chain Management, vol. 8, no. 1, pp. 37-42, 2020.

[30] B. Jing and A. Seidmann, "Finance sourcing in a supply chain," Decision Support Systems, vol. 58, pp. 15-20, 2014.

[31] D. Dash Wu, L. Yang, and D. L. Olson, "Green supply chain management under capital constraint," International Journal of Production Economics, vol. 215, pp. 3-10, 2019.
[32] S. Huang, Z.-P. Fan, and N. Wang, "Green subsidy modes and pricing strategy in a capital-constrained supply chain," Transportation Research Part E: Logistics and Transportation Review, vol. 136, Article ID 101885, 2020.

[33] Y. Su and T. Li, "Simulation analysis of knowledge transfer in a knowledge alliance based on a circular surface radiator model," Complexity, vol. 2020, Article ID 4301489, 27 pages, 2020. 